\title{
Ингаляционный тобрамицин в лечении синегнойной инфекции у больных муковисцидозом
}

ФГУ НИИ пульмонологии ФМБА России: 105077, Москва, ул. 11-я Парковая, 32, к. 4

\author{
E.L.Amelina, A.G.Chuchalin
}

\section{Inhaled tobramycin in treatment of $P$. aeruginosa infection in patients with cystic fibrosis}

Key words: cystic fibrosis, inhaled tobramycin, Pseudomonas aeruginosa.

Ключевые слова: муковисцидоз, ингаляционный тобрамицин, синегнойная палочка.

Муковисцидоз является аутосомно-рецессивным заболеванием с частотой возникновения $1: 2500$ новорожденных в странах Западной Европы и $1: 9000$ в России $[1,2]$. Оно вызвано мутацией гена, ответственного за кодировку белка - муковисцидозного регулятора трансмембранной проводимости (МВТР) [3]. Сокращение транспорта ионов хлора через апикальную мембрану эпителиальных клеток, которое происходит вследствие этого нарушения, приводит к дисфункции поджелудочной железы, печени, желудочно-кишечного тракта, дыхательных путей, потовых желез и репродуктивной системы.

Лежащий в основе заболевания дефект МТВР ведет к развитию бронхолегочной патологии, которая начинается в раннем детском возрасте и после 6 лет вызывает прогрессирующую деградацию легочной функции со средней скоростью $2 \%$ в год [6].

Заболевания легких являются основной причиной смерти у пациентов с муковисцидозом [4]: дыхательная недостаточность становится причиной $90 \%$ летальных исходов [5].

Одним из ключевых факторов прогрессирования болезни легких является хроническая инфекция, вызванная синегнойной палочкой. На ранних стадиях инфицирования дыхательных путей Pseudomonas aeruginosa возможна эрадикация возбудителя в связи с меньшим числом мукоидных штаммов и большей чувствительностью синегнойной палочки к антибиотикам [7].

Европейский консенсус предлагает 3 подхода к лечению инфекций легких у пациентов с муковисцидозом: профилактическое лечение для предотвращения колонизации и инфекции, терапия "по требованию" - при обострении инфекционного бронхолегочного процесса и базисная терапия для увеличения интервала между обострениями и замедления прогрессирования поражения легких [1]. Терапия ингаляционными антибиотиками рекомендуется в качестве поддерживающей терапии у больных муковисцидозом с хронической инфекцией $P$. aeruginosa [1]. Непосредственная доставка антибактериальных препаратов в дыхательные пути имеет следующие преимущества: достижение высокой концентрации действующего вещества в месте инфекции и уменьшение риска системного побочного действия [8, 9]. Внедрение в практику ингаляционной формы тобрамицина в конце 1990-х гг. позволило существенно улучшить прогноз у больных муковисцидозом.

\section{Характеристики новой ингаляционной формы тобрамицина и ее клиническая эффективность}

Тобрамицин - антибиотик из группы аминогликозидов - широко используется для подавления P. aeruginosa у пациентов с госпитальными инфекциями и больных муковисцидозом. До появления ингаляционной формы тобрамицин, предназначенный для внутривенного введения, разбавлялся физиологическим раствором и использовался в ингаляциях через небулайзер.

В настоящее время применяются 2 препарата тобрамицина, специально предназначенного для ингаляций, оба широко используются в Европе, США и Канаде - это Брамитоб ${ }^{\circledR}$ (Chiesi Farmaceuti $S p A$, Италия) и Тоби ${ }^{\circledR}$ (Novartis, Швейцария). Эти препараты предназначены для базисной терапии взрослых и детей, больных муковисцидозом, с инфицированием дыхательных путей P. aeruginosa. В РФ оба препарата были зарегистрированы в мае 2008 г.

1-я появившаяся ингаляционная форма тобрамицина - Тоби - содержит 300 мг тобрамицина в 5 мл физиологического раствора. Брамитоб был разработан с целью улучшения характеристик 1-й ингаляционной формы тобрамицина - Тоби и содержит 300 мг тобрамицина в 4 мл 0,45\%-ного раствора хлорида натрия без консерванта. Объем препарата уменьшен для сокращения времени ингаляции. Ocмолярность Брамитоба (диапазон - от 280 до 350 мосмоль/л) приближена к физиологическому уровню секрета бронхов у пациентов с муковисцидозом [10], с целью снижения риска бронхоспазма при ингаляции препарата.

Эффективность ингаляционного тобрамицина (Тоби, Брамитоб) при лечении больных муковисцидозом, хронически инфицированных P. aeruginosa, была оценена в ряде краткосрочных и длительных 
клинических исследований [11-15]. В краткосрочных исследованиях больные ингалировали 300 мг тобрамицина в виде раствора для ингаляций через небулайзер 2 раза в сутки непрерывно в течение 28 дней [11-13]. В длительных исследованиях 28-дневные курсы лечения чередовались с 28-дневным перерывом, составив, в общей сложности, 24 нед. [14, 15].

Результаты исследования легочной функции, в первую очередь объема форсированного выдоха за 1-ю с $\left(\mathrm{OФВ}_{1}\right)$, являются наиболее достоверным показателем тяжести заболевания и риска смерти больных муковисцидозом [16, 17]. Все исследования, посвященные оценке клинической эффективности ингаляционного тобрамицина, продемонстрировали достоверное улучшение показателей легочной функции (табл. 1). В краткосрочных исследованиях увеличение ОФВ 1 по сравнению с плацебо составило 6-14 \%. Наилучший результат был отмечен в исследовании G.Lenoir et al. при использовании Брамитоба [12], что может быть связано с тем, что у 20 \% пациентов, включенных в исследование, имело место первичное или периодическое инфицирование дыхательных путей синегнойной палочкой, лучше поддающееся антибактериальной терапии. В результате длительных клинических испытаний был также достигнут достоверный прирост ОФВ 1 в группе лечения - 6-12\% (табл. 1). Значимое улучшение функциональных показателей наступало уже на 2-й нед. лечения и сохранялось в течение всего периода долгосрочной (до 96 нед.) интермиттирующей терапии $[14,15,18]$.

Исследования показали, что ингаляционный тобрамицин уменьшает, по сравнению с плацебо, обсемененность синегнойной палочкой мокроты пациентов после краткосрочного [11, 13] и длительного $[14,15]$ курсов лечения. После 3 циклов лечения было отмечено снижение обсемененности мокроты на 0,8 и 1,0 $\log _{10} \mathrm{KOE} / г[14,15]$. У значительного числа пациентов в испытании с использованием Брамитоба после 4 и 20 нед. терапии были получены анализы мокроты, свободные от колоний P. aeruginosa: $31 \%$ и $33 \%$ в группе лечения по сравнению с $14 \%$ и $17 \%$ в группе плацебо соответственно [15]. Кроме того лабораторные исследования продемонстрировали способность тобрамицина снижать вирулентность биофильм-образующей P. aeruginosa в культуре клеток дыхательных путей, пораженных муковисцидозом [21].

Следует отметить, что длительное интермиттирующее лечение ингаляционным тобрамицином сопровождалось снижением чувствительности возбудителя к тобрамицину по сравнению с плацебо $[14,15]$. Так, в группе лечения тобрамицином число пациентов, инфицированных $P$. aeruginosa с минимальной подавляющей концентрацией (МПК) $\geq 16$ мг/л, возросло с $13 \%$ в начале исследования до $23 \%$ на 24-й нед. лечения, по сравнению с $10 \%$ и $8 \%$ соответственно в группе плацебо [22]. При этом улучшение показателей ОФВ 1 не зависело от значения МПК выделенного возбудителя [14, 18]. Возможно, принятое для парентерального тобрамицина пограничное значение МПК (16 мг/л) не адекватно таковому для ингаляционного тобрамицина, т. к. в этом случае концентрация препарата в мокроте значительно превышает МПК для большинства штаммов, считавшихся резистентными к парентеральной терапии.

Проведенные исследования длительной прерывистой терапии ингаляционным тобрамицином не вызвали значимого роста числа возбудителей с природной резистентностью к тобрамицину. Рост Burkholderia cepacia, Stentrophomonas maltophilia и Alcaligenes xyloxidans на 24-й нед. лечения был отмечен у $<1 \%$ пациентов [15, 22]. Примечательно увеличение в мокроте Aspergillus spp. (18\% - в группе лечения и $8 \%-$

Таблица 1

Влияние терапии ингаляционным тобрамицином на показатели респираторной функции и обсемененность мокроты Р. aеruginosa: результаты рандомизированных плацебо-контролируемых исследований

\begin{tabular}{|c|c|c|c|c|c|c|c|c|}
\hline \multirow[b]{2}{*}{ Ссылка } & \multirow[b]{2}{*}{ Препарат } & \multirow[b]{2}{*}{$\begin{array}{c}\text { Доза } \\
\text { (мг / раз в сутки) }\end{array}$} & \multirow[b]{2}{*}{$n$} & \multirow[b]{2}{*}{$\begin{array}{l}\text { OФВ } \\
\text { (\% } \\
\text { нолж.) }\end{array}$} & \multicolumn{4}{|c|}{ Динамика показателей во время исследования } \\
\hline & & & & & $\begin{array}{l}\text { ОФВ }{ }_{1} \\
\left(\%_{\text {долж. }}\right)\end{array}$ & $\begin{array}{l}\text { ФЖЕЛ } \\
\left.\text { (\% }{ }_{\text {допж.) }}\right)\end{array}$ & $\begin{array}{l}\operatorname{COC}_{25-75} \\
\left(\%_{\text {долк. }}\right)\end{array}$ & $\begin{array}{l}\text { степень колонизации } \\
\text { ( } \log _{10} \text { KОЕ / г или мл) }\end{array}$ \\
\hline \multicolumn{9}{|c|}{ Краткосрочные исследования (4 нед.) } \\
\hline \multirow[t]{2}{*}{ B.W.Ramsey et al. [11] } & Тоби & $600 / 3$ & 36 & 55 & $+3,7^{*}$ & $+2,1^{* * *}$ & $6,1^{*}$ & $-2,1^{*}$ \\
\hline & Плацебо & & 33 & 60 & $-6,0$ & $-4,1$ & $-7,0$ & $-0,2$ \\
\hline \multirow[t]{2}{*}{ G.Lenoir et al. [12] } & Брамитоб & $300 / 2$ & 29 & 58 & $+16,1^{* *}$ & $+13,9^{* * *}$ & $+16,3^{* *}$ & -- \\
\hline & Плацебо & & 30 & 60 & $+2,5$ & $+2,6$ & $-0,6$ & -- \\
\hline \multirow[t]{2}{*}{ M.E.Hodson et al. [13] } & Тоби & $300 / 2$ & 53 & 55 & $+6,7^{* * *}$ & -- & -- & $-0,9$ \\
\hline & Колистин & $80 / 2$ & 62 & 59 & $+0,4$ & -- & -- & $-0,6$ \\
\hline \multicolumn{9}{|c|}{ Долгосрочные интермиттирующие исследования (24 нед.) } \\
\hline \multirow[t]{2}{*}{ B.W.Ramsey et al. [14] } & Тоби & $300 / 2$ & 258 & 50 & $+10^{*}$ & $+8,0$ & -- & $-0,8^{*}$ \\
\hline & Плацебо & & 262 & 51 & -2 & $-1,0$ & -- & $+0,3$ \\
\hline \multirow[t]{2}{*}{ A.G.Chuchalin et al. [15] } & Брамитоб & $300 / 2$ & 161 & 61 & $+6,8^{*}$ & $+5,9^{* * *}$ & $8,8^{*}$ & $-1,0^{b}$ \\
\hline & Плацебо & & 86 & 64 & $+0,8$ & $+1,3$ & 0,7 & \\
\hline
\end{tabular}

Примечание: во всех случаях, кроме M.E.Hodson et al. [13], использовался двойной слепой метод; ФЖЕЛ - форсированная жизненная емкость легких; СОС $25-75$ - средняя объемная

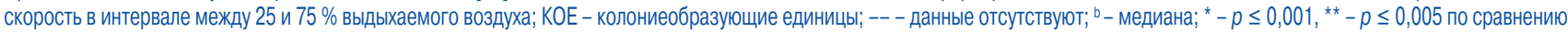
с плацебо; *** - $p \leq 0,05$ по сравнению с плацебо или колистином. 
в группе плацебо), не сопровождающееся развитием грибковой пневмонии, аллергического бронхолегочного аспергиллеза и ростом использования противогрибковых препаратов.

В России Брамитоб исследовался в клинических центрах Москвы, Санкт-Петербурга, Ярославля в 2004 г. в рамках международного многоцентрового исследования. Результаты исследования опубликованы в иностранной и отечественной литературе [15, 38]. Данные об исследовании Тоби на территории РФ отсутствуют.

В настоящее время принята схема интермиттирующей терапии, предусматривающая назначение 300 мг тобрамицина в виде раствора для ингаляций через небулайзер 2 раза в сутки в течение 28 дней с последующим перерывом в 28 дней, после чего терапия повторяется. Таким образом, число курсов терапии составляет 6 в год.

Эффективность данной схемы доказана серией многоцентровых международных рандомизированных клинических исследований для ингаляционного тобрамицина. Потребность 1 пациента в ингаляционном тобрамицине составляет 336 флаконов в год (6 упаковок по 56 флаконов).

\section{Влияние ингаляционного тобрамицина на нутритивный статус}

Индекс массы тела (ИМТ), как самый достоверный показатель состояния питания, является значимым фактором риска смерти у пациентов с муковисцидозом [29, 30]. Обе лекарственные формы ингаляционного тобрамицина увеличивают ИМТ у пациентов с муковисцидозом как после краткосрочной, так и долгосрочной прерывистой терапии $[12,15,20]$. В 2 отдельных исследованиях показано, что после 24 нед. терапии средний ИМТ увеличился на 0,44 и $0,50 \mathrm{\kappa г} / \mathrm{M}^{2}$ от исходного уровня на фоне применения Тоби и Брамитоба соответственно, по сравнению с сокращением или незначительным увеличением в группах плацебо (-0,02 и $0,10 \mathrm{Kг} / \mathrm{M}^{2}$ соответственно) после 24 нед. прерывистой терапии ( $p<0,05$ по сравнению с исходным) $[15,20]$.

\section{Переносимость терапии}

Проведенные исследования показали, что обе лекарственные формы ингаляционного тобрамицина хорошо переносятся пациентами. В отличие от парентеральных, ингаляционные формы тобрамицмна не обладают нефро- или ототоксичностью. Не было отмечено повышения уровня креатинина или ухудшения результатов аудиометрии по сравнению с плацебо при терапии любым из этих препаратов [14, 15, $18,20]$.

Этот результат соответствует низкому уровню концентрации тобрамицина в плазме после ингаляции (<1 мг/л), что значительно ниже, чем концентрация, вызывающая системное токсическое действие (> 10-12 мг/л) [34].

Наиболее распространенными неблагоприятными явлениями, связанными с применением ингаляционного тобрамицина Тоби, являются изменение голоса и звон в ушах $[15,23]$. Побочные эффекты были описаны у бо́льшего процента пациентов, получавших долгосрочную прерывистую терапию Тоби, по сравнению с плацебо. Отмечались звон в ушах (у $3 \%$ и $0 \%$ соответственно; $p=0,003$ ) и изменение голоса (у $13 \%$ и $7 \%$ соответственно; $p=0,02$ ) [14]. Сообщений о жалобах на звон в ушах при использовании Брамитоба не было, изменение голоса было описано у $<1 \%$ пациентов [15].

Бронхоспазм (снижение ОФВ $1>10 \%$ в течение 30 мин после ингаляции) может возникнуть у некоторых пациентов после ингаляции и связан он с конкретными свойствами используемой лекарственной формы (например, pH, консерванты, осмолярность). Бронхоспазм был отмечен у $12 \%$ пациентов, получавших Тоби, в сравнении с $9 \%$ больных, получавших плацебо в ходе 24-недельной прерывистой терапии [31]. Из числа пациентов, получавших Брамитоб, бронхоспазм был отмечен у $<1 \%$ больных [15]. Бронхоспазм, связанный с ингаляцией тобрамицина, можно предотвратить одновременным использованием бронходилататора (например, сальбутамола) [32, 33].

Менышее число местных побочных реакций вследствие приема Брамитоба, по сравнению с Тоби, может быть связано с его осмолярностью, приближенной к значению, полученному на поверхности бронхиального эпителия при муковисцидозе [10].

\section{Фармакоэкономика}

Применение ингаляционного тобрамицина приводит к сокращению числа госпитализаций, курсов внутривенной и таблетированной антибактериальной терапии и пропусков пациентами работы и учебы, что имеет определенные фармакоэкономические последствия.

Тенденция к снижению частоты обострений хронического бронхолегочного процесса отмечалась при использовании ингаляционного тобрамицина, по сравнению с плацебо, как при краткосрочной (3\% и $20 \%$ соответственно; $p=0,06$ ) [11], так и долгосрочной прерывистой терапии (40\% и $51 \%$ соответственно; $p=0,09)$ [15]. Это сопровождалось сокращением потребности в назначении других антибиотиков в группах пациентов, принимающих Тоби и Брамитоб (табл. 2) [14, 15]. Доля больных, нуждающихся в парентеральной антисинегнойной терапии, при применении ингаляционного тобрамицина сокращалась на 20-25\% по сравнению с плацебо [14, 15]. Использование таблетированных фторхинолонов было также уменьшено примерно на $33 \%$ [18]. У пациентов, получавших ингаляционный тобрамицин, отмечалось снижение потребности в других антибиотиках на 19 \% по сравнению с обычной терапией [23].

Обе лекарственные формы ингаляционного тобрамицина сокращали частоту и сроки госпитализации больных муковисцидозом (табл. 2) [14, 15]. Госпитализация оказывает прямое воздействие на качество жизни, условия работы и учебы больных, а также является наиболее дорогостоящим компонентом терапии 
Прерывистая а терапия ингаляционным тобрамицином и расходы на здравоохранение (по данным 24-недельных двойных слепых рандомизированных плацебо-контролируемых исследований)

\begin{tabular}{|c|c|c|c|c|c|c|c|c|}
\hline \multirow[b]{2}{*}{ Ссылка } & \multirow[b]{2}{*}{ Препарат } & \multirow[b]{2}{*}{$\begin{array}{c}\text { Доза } \\
\text { (мг / раз в сутки) }\end{array}$} & \multirow[b]{2}{*}{$n$} & \multicolumn{2}{|c|}{ \% пациентов } & \multicolumn{3}{|c|}{ Средняя продолжительность (число дней) } \\
\hline & & & & $\begin{array}{c}\text { госпитали- } \\
\text { зация }\end{array}$ & $\begin{array}{l}\text { антисинегной- } \\
\text { ные препараты } \\
\text { парентерально }\end{array}$ & $\begin{array}{c}\text { госпитали- } \\
\text { зации }\end{array}$ & $\begin{array}{c}\text { антисинегнойные } \\
\text { препараты } \\
\text { парентерально }\end{array}$ & $\begin{array}{c}\text { пропуск дней } \\
\text { работы / учебы }\end{array}$ \\
\hline \multirow[t]{2}{*}{ B.W.Ramsey et al. [14] } & Тоби & $300 / 2$ & 258 & 37 & 39 & 5,1 & 9,6 & -- \\
\hline & Плацебо & & 262 & 45 & 52 & 8,1 & 14,1 & -- \\
\hline \multirow[t]{2}{*}{ A.G.Chuchalin et al. [15] } & Брамитоб & $300 / 2$ & 161 & $19^{* *}$ & $56^{* * * \mathrm{~b}}(6)^{* * *}$ & -- & -- & $4,7^{*}$ \\
\hline & Плацебо & & 86 & 37 & $70^{\mathrm{b}}(17)$ & -- & -- & 10,0 \\
\hline
\end{tabular}

Примечание: ${ }^{a}$ - 3 последовательных цикла по 28 дней терапии с 28-дневными перерывами; ' - за исключением в/в тобрамицина (в скобках - в/в тобрамицин); -- - данные отсутствуют; ${ }^{*}-p<0,001,{ }^{* *}-p<0,005,{ }^{* * *}-p<0,05$ по сравнению с плацебо.

у этой группы пациентов [24]. Во время долгосрочной прерывистой терапии Брамитоб существенно снижал частоту госпитализаций по сравнению с плацебо (потребность в ней составила $19 \%$ и $37 \%$ соответственно; $(p=0,002)$ [15]. Тоби также снижал частоту госпитализаций по сравнению с плацебо (37\% и $45 \%$ соответственно) [14].

Ингаляционный тобрамицин может также оказывать положительное влияние на трудоспособность пациентов с муковисцидозом. В долгосрочном исследовании активное лечение Брамитобом было связано со значительно меньшим числом пропущенных учебных / рабочих дней по сравнению с плацебо (среднее значение $-4,7$ и 10,0 дней соответственно; $p<0,001)$ [15]. В то же время различий между Тоби и плацебо по числу пропущенных школьных дней у пациентов с поражением легких легкой степени в открытом рандомизированном исследовании отмечено не было. Длительность наблюдения, однако, ограничивалась только 1 циклом лечения [23].

R.Iles et al. [24] провели экономический анализ применения ингаляционного тобрамицина Тоби на основании данных, полученных 8 специализированными центрами по лечению муковисцидоза в Великобритании. Прямые и непрямые расходы на лечение больных в течение года использования ингаляционного тобрамицина и предыдущего года представлены в табл. 3. Результаты этого анализа, являясь отражением фактической клинической практики в Великобритании, подтверждают данные рандомизированных контролируемых исследований, описанных выше (табл. 2). Количество дней пребывания в больнице и назначение внутривенных антибиотиков как косвенные показатели лечения обострений легочной патологии достоверно снижались в течение года на фоне использования ингаляционного тобрамицина (табл. 3). Экономия прямых расходов за счет сокращения этих медицинских ресурсов частично компенсировала расходы на приобретение ингаляционного тобрамицина (табл. 3). Аналогичные выводы были сделаны канадскими исследователями J.LeLorier et al. [28] в анализе, в котором использовались данные государственных расходов на лечение [14].

\section{Качество жизни}

Качество жизни больных муковисцидозом было исследовано в серии работ, приведших к созданию ряда анкет для пациентов [25]. В 2 исследованиях была проведена оценка влияния тобрамицина для ингаляций на качество жизни у больных муковисцидозом с инфекцией P. aeruginosa. В США в большом рандомизированном исследовании $(n=520)$ пациентам (или их родителям) был задан вопрос: улучшилось, ухудшилось или осталось без изменений их состояние после 3 циклов ингаляции препарата (тобрамицина или плацебо). Улучшение качества жизни было более выраженным в группе пациентов, получавших терапию ингаляционным тобрамицином, по сравнению с плацебо $(p<0,05)$ [26]. Аналогичные результаты

таблица 3

Расчет прямых расходов на лечение (по данным обсервационного исследования 41 пациента с муковисцидозом и хронической инфекцией $P$. аеruginosa до и после 1 года использования ингаляџионного тобрамицина) [24]

\begin{tabular}{|c|c|c|c|}
\hline & До использования & Через год использования & Различия \\
\hline \multicolumn{4}{|c|}{ Использование ресурсов здравоохранения* } \\
\hline Продолжительность госпитализации (дней) & 32,0 & 24,2 & $-7,8$ \\
\hline Назначение антибиотиков парентерально (дней) & 55,4 & 38,9 & $-16,4$ \\
\hline \multicolumn{4}{|c|}{ Расходы (фунты) } \\
\hline Ингаляционный тобрамицин & 0 & 10,010 & 10,010 \\
\hline Госпитализация & 10,897 & 8,552 & $-2,345$ \\
\hline Антибиотики & 6,716 & 5,373 & $-1,344$ \\
\hline Другие лекарственные препараты & 4,489 & 4,459 & $-30,000$ \\
\hline Bсего & 22,102 & 28,394 & $+6,292$ \\
\hline
\end{tabular}

Примечание: * - средние значения. 
получены при лечении небольшой группы пациентов $(n=20)$ [27].

\section{Соблюдение режима терапии}

Больные муковисцидозом должны каждый день принимать большое количество лекарственных препаратов в таблетированной и ингаляционной формах, а также проделывать упражнения для улучшения дренажа бронхиального дерева (кинезитерапия). Тщательное выполнение всех компонентов лечения требует от пациента высокой самодисциплины и занимает много времени, поэтому у пациентов с муковисцидозом отмечается снижение показателя приверженности терапии (например, 20 \% соблюдения диетологических рекомендаций) [35].

Тем не менее данные 24-недельного исследования показывают, что соблюдение прерывистой терапии ингаляционным тобрамицином остается неизменно высоким. B.W.Ramsey et al. [14] сообщили, что $88 \%$ пациентов, получавших Тоби, использовали, по крайней мере, 75 \% от полученных ампул. Еще более высокие показатели были отмечены при использовании Брамитоба. В группе пациентов, получавших Брамитоб и плацебо, средний показатель, определяемый как количество больных, использовавших, по меньшей мере, 75 \% от полученных ампул, был равен $99 \%$ [15]. Однако некоторые пациенты могут завышать свои результаты. В США было проведено исследование среди детей, больных муковисцидозом, получающих терапию ингаляционным тобрамицином. Показатели соблюдения режима терапии, основанные на ответах самих пациентов или их родителей, в этом исследовании были 83-85 \%, при этом аналогичный показатель, основанный на данных ежедневных телефонных дневников, не превышал $36 \%$ [36].

Препятствием к максимальному выполнению назначений ингаляционных антибиотиков является, прежде всего, длительность ингаляции и неприятный привкус препарата [35]. И Тоби, и Брамитоб свободны от консервантов, таких, как фенол, имеющий неприятный вкус [32]. Сократить время ингаляции можно за счет использования ингаляции меньшего объема, применяя препарат, имеющий более высокую концентрацию действующего вещества и, соответственно, меньший объем раствора, как Брамитоб [39], либо небулайзеров нового поколения, обладающих высокой производительностью [40, 41], что также может способствовать добросовестному выполнению ингаляционнной терапии.

\section{Заключение}

Включение препаратов ингаляционного тобрамицина (Брамитоба и Тоби) в базисную терапию больных муковисцидозом, инфицированных P. aeruginosa, достоверно уменьшает бронхиальную обструкцию, снижает степень колонизации при хроническом инфицировании и обеспечивает эрадикацию на ранних этапах инфицирования дыхательных путей синегнойной палочкой. К положительным клиническим результатам лечения следует также отнести улучшение нутритивного статуса пациентов и сокращение потребности в других антисинегнойных препаратах, сокращение потери трудоспособности и времени госпитализации. Анализ стоимости, проведенный в Великобритании, показал, что сокращение затрат на госпитализацию и проведение курсов терапии системными антибиотиками, достигнутое при применении ингаляционного тобрамицина, частично компенсирует стоимость этой терапии.

Оба препарата хорошо переносятся пациентами. Длительность ингаляции является главной причиной нарушения пациентами режима терапии. Сoкращение времени ингаляции за счет использования препарата меньшего объема (Брамитоб) или применение небулайзеров нового поколения, может способствовать более добросовестному выполнению назначенного лечения.

\section{Литература}

1. Döring G., Conway S.P., Heijerman H.G.M. et al. Antibiotic therapy against Psudomonas aeruginosa in cystic fibrosis: a European consensus. Eur. Respir. J. 2000; 16: 749-767.

2. Толстова В.Д., Каширская Н.Ю., Капранов Н.И. Массовый скрининг на муковисцидоз в России. Фарматека 2008; 1: 38-43.

3. Zielenski J., Rozmahel R., Bozon D. et al. Genomic DNA sequence of the cystic fibrosis transmembrane conductance regulator (CFTR) gene. Genomics 1991; 10: 214-228.

4. Milla C.E. Nutrition and lung disease in cystic fibrosis. Clin. Chest Med. 2007; 28: 319-330.

5. Cystic Foundation Patient Registry. 2005 annual data report. Maryland; 2006.

6. Cystic Foundation Patient Registry. 1996 annual data report. Maryland; 2006.

7. Gibson R.L., Emerson J., McNamara S. et al. Significant microbiological effect of inhaled tobramycin in young children with cystic fibrosis. Am. J. Respir. Crit. Care Med. 2003; 167: 841-849.

8. Cooney G.F., Lum B.L., Tomaselli M., Fiel S.B. Absolute bioavailability and absorption characteristics of aerosolized tobramycin in adults with cystic fibrosis. J. Clin. Pharmacol. 1994; 34: 255-259.

9. Geller D.E., Pitlick W.H., Nardella P.A. et al. Pharmacokinetics and bioavailability of aerosolized tobramycin in cystic fibrosis. Chest 2002; 122: 219-226.

10. Knowles M.R., Robinson J.M., Wood R.E. et al. Ion composition of airway surface liquid of patients with cystic fibrosis as compared with normal and disease control subjects. J. Clin. Invest. 1997; 100: 2588-2595.

11. Ramsey B.W., Dorkin H.L., Eisenberg J.D. et al. Efficacy of aerosolized tobramycin in patients with cystic fibrosis. N. Engl. J. Med. 1993; 328: 1740-1746.

12. Lenoir G., Antypkin Y.G., Miano A. et al. Efficacy, safety, and local pharmacokinetics of highly concentrated nebulized tobramycin in patients with cystic fibrosis colonized with Pseudomonas aeruginosa. Pediatr. Drugs 2007; 9: 11-20.

13. Hodson M.E., Gallagher C.G., Govan J.R.W. A randomised clinical trial of nebulised tobramycin or colistin in cystic fibrosis. Eur. Respir. J. 2002; 20: 658-664.

14. Ramsey B.W., Pepe M.S., Quan J.M. et al. Intermittent administration of inhaled tobramycin in patients with cystic fibrosis. N. Engl. J. Med. 1999; 340: 23-30. 

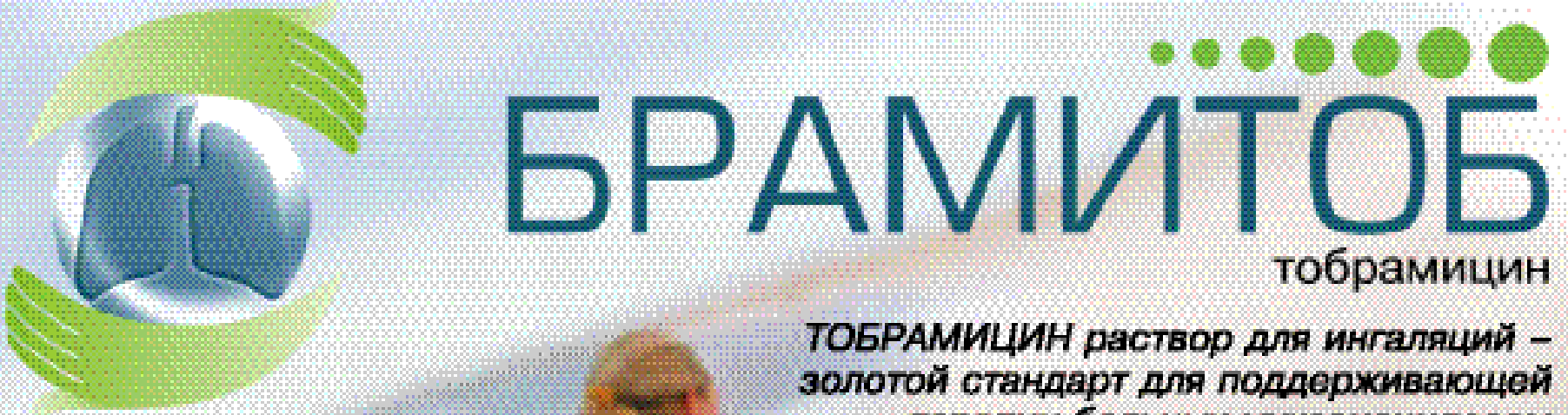

ТОБРАМИЦИН раствор для ингаляЧий золотой стандарт для поддерживающей терапии больных муковисцидозом с хронической инфекиией P. AERUGINOSA

- Более высокая концентрация тобрамицина в БРАМИТОБе позволяет достичь более высокого содержания действующего вещества в мокроте'

- БРАМИТОБ сокращает время ингаляции на $30 \%$ no сравнению с другими ингаляционными формами тобрамицина'

- БРАМИТОБ мИнимизирует риск развития нежелательных эффектов, включая бронхоспазм 1.2

- БРАМИТОБ увеличивает приверженность пациентов ингаляционной терапии тобрамицином²

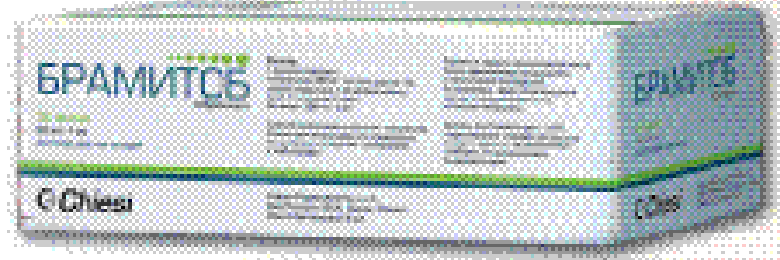

БРАМИТОБ НА ПЕРЕДНЕМ КРАЕ ЗАЩИТЫ ЛЁГКИХ У БОЛЬНЫХ МУКОВИсцидозОМ

תCP-003882/08 Ten./фakc: $+7(495) 96712$ 12, $\theta$-mail: info(echiesirussia.com 
15. Chuchalin A., Gyurkovics K., Bartnicka M.T. et al. A formulation of aerosolized tobramycin $\left(\right.$ Bramitob $\left.^{\circledR}\right)$ in the treatment of patients with cystic fibrosis and Pseudomonas aeruginosa infection: a double-blind, placebo-controlled, multicenter study. Pediatr. Drugs 2007; 9: 21-31.

16. Kerem E., Reisman J., Corey M. et al. Prediction of mortality in patients with cystic fibrosis. N. Engl. J. Med. 1992; 326: 1187-1191.

17. Ramsey B.W., Boat T.F. Outcome measures for clinical trials in cystic fibrosis: summary of a Cystic Fibrosis Foundation consensus conference. J. Pediatr. 1994; 124: 177-192.

18. Moss R.B. Administration of aerosolized antibiotics in cystic fibrosis patients. Chest 2001; 120: 107S-113S.

19. Marostica P.J., Weist A.D., Eigen H. et al. Spirometry in 3to 6-year-old children with cystic fibrosis. Am. J. Respir. Crit. Care Med. 2002; 166: 67-71.

20. Moss R.B. Long-term benefits of inhaled tobramycin in adolescent patients with cystic fibrosis. Chest 2002; 121: 55-63.

21. Anderson G.G., Moreau-Marquis S., Stanton B.A., O'Toole G.A. In vitro analysis of tobramycin-treated Pseudomonas aeruginosa biofilms on cystic fibrosis-derived airway epithelial cells. Infect. and Immun. 2008; 76: 1423-1433.

22. Burns J.L., Van Dalfsen J.M., Shawar R.M. et al. Effect of chronic intermittent administration of inhaled tobramycin on respiratory microbial flora in patients with cystic fibrosis. J. Infect. Dis. 1999; 179: 1190-1196.

23. Murphy T.D., Anbar R.D., Lester L.A. et al. Treatment with tobramycin solution for inhalation reduces hospitalizations in young $\mathrm{CF}$ subjects with mild lung disease. Pediatr. Pulmonol. 2004; 38: 314-320.

24. Iles R., Legh-Smith J., Drummond M. et al. Economic evaluation of Tobramycin nebuliser solution in cystic fibrosis. J. Cyst. Fibros. 2003; 2: 120-128.

25. Weiner J.R., Toy E.L., Sacco P., Duh M.S. Costs, quality of life and treatment compliance associated with antibiotic therapies in patients with cystic fibrosis: a review of the literature. Expert. Opin. Pharmacother. 2008; 9: 751-766.

26. Quittner A.L., Вии A. Effects of tobramycin solution for inhalation on global ratings of quality of life in patients with cystic fibrosis and Pseudomonas aeruginosa infection. Pediatr. Pulmonol. 2002; 33: 269-276.

27. Hill D.M., Fukushima L.K., Hsu E., Woo M.S. Obstacles to use of high-dose aerosolized tobramycin in eligible cystic fibrosis patients. In: American Thoracic Society Conference, 2005.

28. LeLorier J., Perreault S., Birnbaum H. et al. Savings in direct medical costs from the use of tobramycin solution for inhalation in patients with cystic fibrosis. Clin. Ther. 2000; 22: $140-151$.
29. Courtney J.M., Bradley J., Mccaughan J. et al. Predictors of mortality in adults with cystic fibrosis. Pediatr. Pulmonol. 2007; 42: 525-532.

30. Stern M., Wiedemann B., Wenzlaff P. The German CFQA Group from registry to quality management: The German CF Quality Assessment project 1995-2006. Eur. Respir. J. 2008; 31: 29-35.

31. Lamb H.M., Goa K.L. Management of patients with cystic fibrosis: defining the role of inhaled tobramycin. Dis. Manage Hlth Outcomes 1999; 6: 93-108.

32. Nikolaizik W.H., Trociewicz K., Ratjen F. Bronchial reactions to the inhalation of high-dose tobramycin in cystic fibrosis. Eur. Respir. J. 2002; 20: 122-126.

33. Ramagopal M., Lands L.C. Inhaled tobramycin and bronchial hyperactivity in cystic fibrosis. Pediatr. Pulmonol. 2000; 29: 366-370.

34. AHFS drug information 2006. Tobramycin sulfate. http://www.ashp.org/ahfs/first_rel/Revised-tobramycin_ oct2006.pdf [accessed 1 Nov 2007]

35. Modi A.C., Quittner A.L. Barriers to treatment adherence for children with cystic fibrosis and asthma: What gets in the way? J. Pediatr. Psychol. 2006; 31: 846-858.

36. Modi A.C., Lim C.S., Yu N. et al. A multi-method assessment of treatment adherence for children with cystic fibrosis. J. Cyst. Fibros. 2006 5: 177-185.

37. Kerem E. Early intervention in CF: When to start treatment and how to measure response? Cyst. Fibros. Worldwide Newslett. 2006; 8 (2): 10-14.

38. Капранов Н.И., Каширская Н.Ю., Радионович А.М. и др. Клиническое значение специальной аэрозольной формы тобрамицина в лечении хронического бронхолегочного процесса у больных муковисцидозом. Пульмонология 2008; 3: 20-26.

39. Poli G., Acerbi D., Pennini R. et al. Clinical pharmacology study of Bramitob ${ }^{\circledR}$, a tobramycin solution for nebulization, in comparison with Tobi ${ }^{\circledR}$. Pediatr. Drugs 2007; 9: 3-9.

40. Schneiders A.M., Pechtold O., Sommerer K. et al. In vitro characterization of BRAMITOB ${ }^{\circledR}$ (inhaled tobramycin $300 \mathrm{mg} / 4 \mathrm{ml}$ ) with next generation nebulisers. Congress of the Italian Cystic Fibrosis Society, 2007.

41. Hubert D., Leroy S., Dominique S., Kovarik J. Pharmacokinetic comparison of inhaled tobramycin $\left(\mathrm{TOBI}^{\circledR}\right)$ via PARI eFlow ${ }^{\circledR}$ rapid or PARI LC PIusTM nebulizers in cystic fibrosis patients. J. Cyst. Fibros. 2007; 6 (Suppl. 1): S12 (abstract A050 and poster).

\section{Информация об авторах}

Амелина Елена Львовна - к. м. н., зав. лабораторией муковисцидоза НИИ пульмонологии ФМБА России, тел. (495) 465-53-84; e-mail: eamelina@mail.ru

Чучалин Александр Григорьевич - акад. РАМН, д. м. н., проф., директор ФГУ НИИ пульмонологии ФМБА России; тел.: (495) 465-52-64 